\title{
Life cycle assessment of thermal Waste-to-Energy technologies: Review and recommendations
}

\author{
Astrup, Thomas Fruergaard; Tonini, Davide; Turconi, Roberto; Boldrin, Alessio
}

Published in:

Waste Management

Link to article, DOI:

10.1016/j.wasman.2014.06.011

Publication date:

2015

Document Version

Peer reviewed version

Link back to DTU Orbit

Citation (APA):

Astrup, T. F., Tonini, D., Turconi, R., \& Boldrin, A. (2015). Life cycle assessment of thermal Waste-to-Energy technologies: Review and recommendations. Waste Management, 37, 104-115.

https://doi.org/10.1016/i.wasman.2014.06.011

\section{General rights}

Copyright and moral rights for the publications made accessible in the public portal are retained by the authors and/or other copyright owners and it is a condition of accessing publications that users recognise and abide by the legal requirements associated with these rights.

- Users may download and print one copy of any publication from the public portal for the purpose of private study or research.

- You may not further distribute the material or use it for any profit-making activity or commercial gain

- You may freely distribute the URL identifying the publication in the public portal

If you believe that this document breaches copyright please contact us providing details, and we will remove access to the work immediately and investigate your claim. 


\title{
Life Cycle Assessment of Thermal Waste-to-Energy Technologies: Review and Recommendations
}

\author{
Astrup, T.F.; Tonini, D.; Turconi, R. and Boldrin, A. \\ Department of Environmental Engineering \\ Technical University of Denmark \\ Kgs. Lyngby, Denmark
}

"NOTE: this is the author's version of a work that was accepted for publication in Waste Management journal. Changes resulting from the publishing process, such as peer review, editing, corrections, structural formatting, and other quality control mechanisms may not be reflected in this document. Minor changes may have been made to this manuscript since it was accepted for publication. A definitive version is published in Waste Management, vol 37, pp 104-115, doi:10.1016/j.wasman.2014.06.011" 


\section{Abstract}

24 Life cycle assessment (LCA) has been used extensively within the recent decade to 25 evaluate the environmental performance of thermal Waste-to-Energy (WtE) 26 technologies: incineration, co-combustion, pyrolysis and gasification. A critical review 27 was carried out involving 250 individual case-studies published in 136 peer-reviewed 28 journal articles within 1995 and 2013. The studies were evaluated with respect to 29 critical aspects such as: i) goal and scope definitions (e.g. functional units, system 30 boundaries, temporal and geographic scopes), ii) detailed technology parameters (e.g. 31 related to waste composition, technology, gas cleaning, energy recovery, residue 32 management, and inventory data), and iii) modeling principles (e.g. energy/mass 33 calculation principles, energy substitution, inclusion of capital goods and uncertainty 34 evaluation). Very few of the published studies provided full and transparent descriptions of all these aspects, in many cases preventing an evaluation of the validity of results,

36 and limiting applicability of data and results in other contexts. The review clearly 37 suggests that the quality of LCA studies of WtE technologies and systems including 38 energy recovery can be significantly improved. Based on the review, a detailed 39 overview of assumptions and modeling choices in existing literature is provided in 40 conjunction with practical recommendations for state-of-the-art LCA of waste-to41 energy.

\section{1. Introduction}

44 Energy recovery from waste is an essential part of modern waste management. Within the last decades, waste management has changed from being a sector primarily focusing on treatment and final disposal of residual streams from society to now being a sector

47 that contributes significantly to energy provision and secondary resource recovery. In 
the transition towards more sustainable energy supply, energy recovery from waste is gaining increasing interest as an option for reducing dependence on imported fossil fuels. In a future with higher shares of intermittent energy sources such as wind and photo voltaic, and phase-out of coal, energy recovery from waste may provide an alternative to increased used of constrained non-fossil resources such as biomass.

Within the recent decade, life cycle assessment (LCA) has been used extensively to evaluate the environmental benefits and drawbacks of waste management, including energy recovery technologies. Both individual waste-to-energy (WtE) technologies (among the others Scipioni et al., 2009, Boesch et al., 2014, Turconi et al., 2011, Tonini et al., 2013, Møller et al., 2011) as well as the role of these technologies within the entire waste management systems (among the others Eriksson et al., 2007, Finnveden et al., 2007, Finnveden et al., 2005, Fruergaard et al., 2010, Moberg et al., 2005, Manfredi et al., 2011, Christensen et al., 2009, Merrild et al., 2012, Song et al., 2013, Tunesi, 2011, Bernstad and la Cour Jansen, 2011, Rigamonti et al. 2014) have been assessed. While anaerobic degradation of organic waste is a well-established technology, today energy recovery based on thermal conversion of waste is the most widespread WtE technology (ISWA, 2012). The main thermal technologies are: i) waste incineration at dedicated plants, ii) co-combustion with other fuels, iii) thermal gasification, and iv) thermal pyrolysis. While mass-burn waste incineration generally is the most robust technology accepting a wide range of waste materials (size, sources), also other 68 technologies such as fluidized-bed incineration exist (a more homogeneous waste input 69 is needed here). Co-combustion, gasification, and pyrolysis are generally less widespread and mainly applied on pre-treated waste or sub-streams of urban waste (e.g. Solid Recovered Fuels, SRF, or Refuse Derived Fuels, RDF). 
Although LCA as an assessment tool is fairly mature and overall assessment

73 guidelines exist outlining the main assessment principles, relatively little methodological consistency exist between individual LCA studies in literature as highlighted by Laurent et al. (2014a, 2014b). Technology modeling principles, LCA principles (e.g. attributional vs. consequential assessment), choices of impact assessment methodologies, key WtE technology parameters (e.g. energy recovery efficiencies), emission levels, and choices related to the environmental value of energy substitution varies significantly between LCA studies (Laurent et al., 2014a). Existing LCA guidelines (e.g. ISO 2006a and ISO 2006b) attempt to overcome these inconsistencies by providing a more standardized framework for performing and reporting LCA studies. However although these guidelines are extremely valuable, the concrete implementation of the provided assessment principles still allow ample room for interpretation. Consequently, in some cases LCA results can be found in literature indicating that anaerobic digestion is preferable (e.g. Khoo et al., 2010) while waste incineration may appear optimal in other cases (e.g. Manfredi et al., 2011, Fruergaard and Astrup, 2011), seemingly based on similar waste types or similar technologies. Methodological challenges and inconsistencies in relation to LCA is not specific for WtE technologies (Laurent et al., 2014a, 2014b); however as WtE technologies may play an increasingly important role in many countries, a detailed and systematic review

91 of assessment choices and inventory data specifically related to thermal WtE 92 technologies are needed. Reaching robust and widely accepted conclusions based on the 93 variety of results in existing LCA studies of WtE technologies requires detailed insight 94 and understanding of the specific systems modeled in the studies as well as the LCA modeling principles applied in the individual studies. This substantially limits the usability of LCA results for decision-makers and opens for yet other LCA case-studies 
97 which may not provide novel insights from a research perspective. Consequently, this

98 situation may significantly limit the overall value of LCA studies for future

99 implementation of $\mathrm{WtE}$ technologies in society.

100 The demand for consistency and transparency within waste LCA is increasing

101 dramatically and to perform state-of-the-art LCA studies, a systematic overview of

102 modeling and assessment choices is needed. The aim of this paper is to provide such an

103 overview based on a critical review of existing LCA studies of WtE in literature,

104 focusing on thermal $\mathrm{WtE}$ technologies. The specific objectives are: i) to critically

105 analyze existing LCA studies involving $\mathrm{WtE}$ technologies with respect to key

106 assessment choices, ii) to identify the most important methodological aspects and

107 technology parameters, and iii) to provide recommendations for state-of-the-art LCA of

108 WtE technologies.

109

110 2. Methodology

111 2.1. Selection of papers for review

112 LCA of waste management technologies and systems has gained momentum within the

113 last 10-15 years and the approaches used have developed significantly in the same

114 period (Laurent et al., 2014a, 2014b, Ekvall et al., 2007, Finnveden et al., 2009).

115 Existing literature therefore covers considerable variations with respect to focus and

116 approach. To ensure consistency, literature included in the review was selected based on

117 the following overall criteria: i) the study was published in a peer-reviewed scientific

118 journal; ii) the LCA study focused on waste management and included at least one

119 thermal WtE technology as a key part of the study; iii) an impact assessment was

120 performed and more than one impact category was included; and iv) the study was

121 reported in English. Studies published until December 2013 were included. 


\section{2.2. Review approach}

124 The review addressed the following main aspects: i) definition of goal and scope of the 125 study, ii) description of technical parameters and life cycle inventory (LCI) data, iii)

126 methodological choices of LCA modeling. An overview of these aspects is provided in 127 Table 1.

128 In relation to "goal and scope definition", it was assessed whether a clear and 129 comprehensive description of the study context was provided. The aim was thereby to 130 qualitatively evaluate how appropriate the LCA modeling described the system in 131 question. The description of technical parameters concerning thermal WtE processes 132 and the influence of these parameters on the results were evaluated. The waste input to 133 the WtE technology was evaluated with respect to the description of the waste type (all 134 waste types typically addressed in "waste management studies" were included: e.g. 135 households waste, mixed municipal solid waste, RDF/SRF, combustible industry waste, 136 or single fractions), waste composition (i.e. presence of individual material fractions 137 and their chemical composition) and the origin of these data. Key technology aspects of 138 the WtE processes were evaluated relative to thermal technology, energy recovery, and 139 residue management: i) plant type, ii) energy recovery and type of energy output, iii)

140 flue gas cleaning techniques (e.g. air-pollution-control: dust removal, acid gas 141 neutralization, deNO $\mathrm{x}_{\mathrm{x}}$, etc.), and iv) residue types, generation and management. Finally, 142 available quantitative data for emissions and consumption of energy/materials were 143 extracted from the reviewed studies.

144 Key methodological aspects of the reviewed studies were addressed focusing on:

145 i) the overall modeling approach and whether the study accounted for and balanced 146 mass and energy flows, ii) inclusion of capital goods, iii) energy substitution principles, 
147 and iv) inclusion of uncertainty and/or sensitivity analysis. Finally, overall trends in

148 results between the reviewed studies were identified and discussed.

\section{$150 \quad 3$. Results and discussion}

151 A total of 136 journal articles were identified, including 250 individual case-studies of

152 technologies for thermal treatment of waste (Figure 1). The complete list of studies is

153 provided in the supplementary material (Table S13). Only few studies were performed

154 prior to 2002, no studies before 1995 was found. Throughout the following sections,

155 comparability between studies is discussed and understood as the possibility for the

156 reader to appreciate the LCA results based on transparent reporting of assumptions,

157 assessment methodology, technical parameters, etc.

\section{$159 \quad 3.1$ Goal and scope definition}

160 Goal and scope definition includes specification of the aim of the study, its functional

161 unit (FU, quantitatively and qualitatively describing the service provided by the

162 assessed system), and the corresponding system boundaries. Goal and scope definitions

163 are fundamental for the interpretation of results and thereby for the outcome of LCA

164 studies (Laurent et al., 2014b, Finnveden et al., 2009, ISO 2006a, ISO 2006b). Most of

165 the reviewed case-studies applied an FU defined with respect to the waste input, e.g. as

166 a unit mass of waste received at the WtE facility (58\% of the case-studies). This FU

167 indicates an assessment perspective related to "waste management" or "treatment of X

$168 \mathrm{Mg}$ of waste", which subsequently allows comparison between individual "treatment

169 technologies". About $28 \%$ of the case-studies had a FU represented by the waste

170 generation in a given area or region. Relatively few case-studies had FUs related to

171 specific inputs or outputs from the WtE facilities, or did not define the FU at all. About 
$17268 \%$ of the LCA case-studies either compared several WtE technologies against each

173 other, or compared WtE with other waste management options. In addition to the $68 \%$

174 of case-studies comparing specific technologies, about $26 \%$ of the studies included

$175 \mathrm{WtE}$ as an integrated part of a waste management system in combination with other 176 technologies, e.g. Arena et al. (2003) and Tonini and Astrup (2012). Very few studies

177 applied LCA for process optimization: only 12 case-studies (5\%) used LCA for 178 improvement of specific sub-units of individual plants (e.g. Scipioni et al., 2009, Møller 179 et al., 2011). Figure 2 provides an overview of goal and scope related aspects.

180 The waste input to the $\mathrm{WtE}$ facility is the starting point of the energy recovery 181 process and is therefore essential for the LCA study (Laurent et al., 2014a, 2014b).

182 Within the reviewed case-studies, a wide variety of waste materials have been 183 addressed: from mixed household waste to single material fractions. About $38 \%$ of the 184 studies defined the waste input as "mixed municipal waste" and "residual municipal 185 waste", while another $16 \%$ addressed pre-treated waste (e.g. Solid Recovered Fuels, 186 SRF) and yet another $27 \%$ focused on single material fractions in the waste.

187 Time horizon, geographical and temporal scopes are important within LCA for 188 the applicability of the results and comparability with similar studies (Laurent et al., 189 2014a, 2014b, Finnveden et al., 2009, ISO 2006a, ISO 2006b, Finnveden, 1999, 190 Turconi et al., 2013). Most of the studies did not define the time horizon (75\%), 191 thereby not transparently reporting the included emissions and/or addressing the 192 dynamics e.g. related to long-term emissions from solid residues. A little less than half $193(43 \%)$ of the studies did not specify the temporal scope, i.e. the time period that the 194 technology and assessment addressed. Conversely, most studies (96\%) mentioned the 195 country or regional settings of the study. 
197 studies managed to provide full descriptions of the goal and scope (i.e. including 198 detailed and transparent descriptions of the functional unit, the goal of the study, the

199 time horizon, the geographical and temporal scopes), thereby essentially preventing 200 direct comparison of results between studies and at the same time limiting the 201 possibilities for full apprehension of the provided conclusions.

\subsection{Key technical parameters}

\subsubsection{Waste composition}

205 While the waste type addressed in the studies is important for the overall framework of

206 the study, the detailed composition of the waste may be critical with respect to the 207 emissions from the WtE facilities (e.g. Astrup et al., 2011). While $70 \%$ of the case208 studies provided a detailed description of the material fractions present in the waste (i.e. 209 quantities of plastic, paper, organic materials, etc.), only $44 \%$ provided information 210 about the chemical composition of the waste and/or material fractions (see Figure 3).

211 About $18 \%$ of the studies provided no description at all regarding chemical 212 composition, while $8 \%$ provided only very limited description. This clearly represents a 213 limitation with respect to the LCA modeling as many emissions from thermal processes

214 (e.g. metals) are affected by the waste input chemistry (i.e. the emission represents a 215 certain fraction of the input quantity, e.g. Astrup et al., 2011). Although the lower 216 heating value (LHV) of the waste can be considered a critical parameter in relation to 217 WtE, LHV was reported in only $57 \%$ of the case-studies, ranging between values such 218 as $1.4 \mathrm{MJ} / \mathrm{kg}$ ww (food waste, Nakakubo et al., 2012) and $46.9 \mathrm{MJ} / \mathrm{kg}$ ww (PET plastic, 219 Xie et al., 2013). 
For those studies actually including waste composition data, the traceability of the included data was limited. Of the studies including composition data, $18 \%$ did not report the origin of the data for material fractions, and $40 \%$ did not specify the origin of data for chemical composition (i.e. providing a clear reference to publications providing

224 the information). Omitting waste composition data in relation to LCA of WtE technologies significantly reduces the transparency of the study, but also render the results questionable as i) it may be unclear to which extent the study addresses contaminants in the waste, and ii) essentially prevent reproducibility of the study.

\subsubsection{Thermal technologies}

230 Mass-burn incineration based on moving grate systems was the most frequently 231 assessed technology. About $82 \%$ of the case-studies focused on incineration; about half of these specified that the technology involved a moving grate (Figure 4). Significantly less attention has been placed on other WtE technologies such as pyrolysis, gasification, co-combustion in power plants and in cement-kilns. For a more balanced understanding of the environmental performance of $\mathrm{WtE}$ technologies, this clearly suggests that more studies are needed focusing on other technologies than incineration. Generally, air-pollution-control (APC) systems were very poorly described. Figure 5 illustrates that more than $50 \%$ of the case-studies did not describe the specific technology applied. This essentially prevents verification of the inventories (if

240 provided) for emissions and material/energy consumption, thereby preventing the

241 applicability of the studies to be evaluated. Omitting information about gas cleaning also significantly reduces transparency with respect to geographical and temporal scope,

243 i.e. whether the technology is typical for the region and time period assessed. Only a

244 few case-studies clearly specified that individual gas cleaning units were not present, 
e.g. in the case of poor or old plants (Morselli et al., 2007, Liamsanguan and Gheewala, 2007).

\subsubsection{Energy recovery}

249 Energy recovery is one of the most important technical aspects of WtE technologies and 250 critical for the outcome of LCA studies (e.g. Boesch et al., 2014, Turconi et al., 2011, 251 Tunesi, 2011, Turconi et al., 2013). Figure 6 presents an overview of how energy recovery was included in the reviewed case-studies. Energy recovery was included in about $83 \%$ of the studies, with electricity recovery being most important ( $73 \%$ of the case-studies), while heat was the only energy type recovered in $10 \%$ of the studies. About $5 \%$ of the studies clearly stated that no energy recovery was performed at the plant. About $12 \%$ of the studies did not mention energy recovery at all. Of the 183 case-studies including electricity as an energy recovery option, $37 \%$ stated the gross electric efficiency, while $52 \%$ mentioned the net electricity efficiency. Of the casestudies including heat recovery, $59 \%$ reported the net heat recovery used in the modeling (if no details were provided, net heat recovery was assumed).

An overview of the reported recovery efficiencies is provided in Table 2, including average values calculated for individual technologies. The numerical variations are considerable, most likely as a result of geographical and temporal differences between studies. For those studies reporting the temporal scope of the LCA

265 (i.e. $43 \%$ ), the recovery efficiencies were plotted against the temporal scope of the 266 study (see Figure S2 in the supplementary material). No clear trends for temporal 267 developments could be identified; however, large variations could be observed within 268 similar temporal scopes, suggesting that other factors had a larger influence on the 269 energy recovery efficiencies than temporal scope of the study. 

and 0 to almost $88 \%$ (heat), illustrating the wide variety of specific technologies and/or

272 facilities assessed in the reviewed studies. Although only very few studies of other 273 technologies than incineration existed, electricity efficiencies for co-combustion 274 appeared to be in the upper end of the range for incineration, while heat efficiencies 275 appeared to be significantly lower than for incineration. Gasification and pyrolysis 276 efficiencies could not be compared directly as the reported efficiencies were based on 277 gas-to-energy output conversion, excluding the syngas generation itself. Difference in heat recovery between incinerators may not necessarily be related to technological

279 features, but may also be a consequence of local heat markets (e.g. Fruergaard et al., 2802010 ). About $59 \%$ of the case-studies related the energy recovery to the energy content of the waste itself, while $31 \%$ of the studies did not specify how the energy calculations were performed. A few cases used default values from literature $(2 \%)$ or measured data $(4 \%)$.

\subsubsection{Residue management}

286 Residue management was included only in about half of the case-studies (see Figure S3, supporting material). About $34 \%$ did not specify whether or how residues were included in the modeling. Only in $11 \%$ of the cases, the studies specified that residue management was intentionally excluded. In these cases, the justification was generally that residue management was not a "significant issue" overall; however, without

291 providing evidence or support for the statement.

Of the studies providing information about residue management, the fate of the residues was generally poorly described (see Figure 7). Regarding APC residues

294 (considered a combination of neutralization products and fly ashes unless otherwise 
specified) and sludge from treatment of wastewater, more than $60 \%$ of the case-studies did not specify the management. Bottom and fly ashes were somewhat better addressed

297 with, respectively, around $42 \%$ and $55 \%$ of the studies specifying the management of these ashes, respectively. In both cases, landfilling was the most commonly used option, rather than recovery and material utilization. While the reviewed studies focusing on

300 WtE technologies may cover residue management only to a limited extent, a few studies

301 in literature provide dedicated LCA modeling of the management of APC residues (e.g.

302 Fruergaard et al., 2010) as well as utilization vs. landfilling of bottom ashes (e.g.

303 Birgisdottir et al., 2007).

\subsubsection{Material/energy and emissions inventories}

306 Input-output inventory tables are typically used to provide overview of all relevant 307 inputs (e.g. material and energy consumption) to WtE technologies as well as outputs

308 (e.g. air emissions). Only $14 \%$ of the case-studies provided detailed inventory data.

309 About $57 \%$ of the cases provided part of the inventories, in several cases limited to 310 very few data.

311 Besides completeness, the origin and quality of the inventory data may be of 312 significant importance. For about $32 \%$ of the case-studies, no information concerning 313 the origin of inventory data was provided. About $20 \%$ and $6 \%$ of the studies applied 314 data from literature and databases, respectively (see Figure S4, supplementary material).

315 In only about $34 \%$ of the case-studies, actual emission data originating from specific

316 measurements related to the assessed system was included; the data mainly originated 317 from full-scale facilities (i.e. $30 \%$ ).

318 For most parameters, extremely large variations (up to $>10$ orders of magnitude 319 in some cases) could be observed across the reviewed studies (see Table S10, 
supplementary material). These large variations were especially pronounced for

321 emissions of trace compounds to air (e.g. PCDD/F, $\mathrm{Hg}, \mathrm{Cd}$, and As), but also for in-

322 plant consumption of electricity and auxiliary fuels. These discrepancies in inventory

323 data can only partly be explained by technological differences and variations in

324 geographical and temporal scope of the studies. For example, systematic comparisons of

325 historical developments in air-pollution-control systems (Damgaard et al., 2010) have

326 demonstrated far less variations in air emissions, and thereby also environmental

327 impacts, than the variations indicated by the reviewed studies.

328 While not possible to examine based on the reviewed studies themselves, some

329 of the observed differences in inventory data may be potential mistakes, either related to

330 the data generation or the manuscript writing. Examples are PCDD/F emissions in the

331 order of $600 \mathrm{mg} / \mathrm{Mg}$ of waste (Hong et al., 2006), $\mathrm{Hg}$ emissions of $15 \mathrm{~g} / \mathrm{Mg}$ of wood

332 waste in case of steam gasification (Khoo et al., 2009), and oil consumption of more

333 than $300 \mathrm{~kg} / \mathrm{Mg}$ of waste in a fluidized bed reactor (Ning et al., 2013). These values are

334 significantly higher than most other studies and the values should at least have been

335 argued relative to typical values found in literature.

336 Inventory data can be considered critical for the transparency of an individual

337 study. But as specific inventory data from one study are often re-used by other studies

338 in new LCA modeling contexts, the need for critical evaluation of values and

339 comparison with well-documented studies in literature, before LCA modeling, should

340 be evident.

$342 \quad 3.3$ Key methodological choices

$343 \quad$ 3.3.1 LCI modeling approach 
344 The approach used for modeling of emissions and energy recovery in LCA of WtE

345 technologies is potentially more important than in other types of LCA (Damgaard et al., 346 2010, Hellweg et al., 2001, Turconi et al., 2011), as these two aspects represent the

347 main environmental loads and potential benefits. In $55 \%$ of the case-studies, the LCI 348 data appeared or was claimed to be based on mass and energy balances (see Figure 8).

349 In about $30 \%$ of the cases, transfer coefficients (TC) were used to correlate the waste

350 input composition (chemistry and energy content) with the outputs from the WtE 351 process. Very few of these studies applied TCs to balance only mass or only energy (2

$352 \%$ and $8 \%$, respectively, of all cases). Another third of the case-studies $(27 \%)$ did not 353 mention applying any form of mass and energy balancing, suggesting that emissions 354 and/or flows in these cases could be inaccurate. The remaining third of the studies (33 $355 \%$ applied some level of mass and/or energy balancing, but without specifying 356 correlations between inputs and outputs. In such cases, the LCA modeling results may 357 not be directly applicable to situations where the same WtE technology is used in the 358 context of different waste input compositions. Without sufficient information about the 359 modeling approach, the results may potentially include a significant (but unquantifiable) 360 error.

\subsubsection{Capital goods}

363 The environmental impacts related to capital goods, i.e. facilities and equipment, have

364 only very recently been addressed systematically (e.g. Brogaard et al., 2013). In relation

365 to WtE technologies, capital goods may have a significant influence on the LCA results, 366 in particular for impact categories such as resource depletion, eutrophication and 367 toxicity related impact categories (Brogaard et al., 2013). Only $19 \%$ of the reviewed 368 case-studies included capital goods (see Figure 9), while about $58 \%$ of the studies did 
not specify whether capital goods were included. About $23 \%$ of the case-studies

370 reported that capital goods were intentionally excluded based on an argument that the contribution was negligible overall. Based on recent literature, however, this conclusion is questionable if an LCA involves aspects such as resource depletion, eutrophication and toxicity related impacts.

\subsubsection{Avoided burdens from energy production}

376 Of the 238 case-studies in which energy recovery was considered (assuming that energy

377 was recovered unless explicitly stated as "not recovered"), substitution of energy within

378 the energy system was modelled in $83 \%$ of the cases by means of system expansion

379 (see Figure 10, left). In $6 \%$ of the case-studies, energy substitution was not included 380 and environmental benefits from avoided production of energy and saving of fuels were not addressed. Only in $11 \%$ of the case-studies energy substitution was included but not specified. Considering the importance of energy substitution for the overall LCA results (Finnveden et al., 2005, Moberg et al., 2005, Laurent et al., 2014a, 2014b,

384 Finnveden et al., 2009), the high share of studies including avoided energy production is encouraging.

Various approaches for quantification of the substituted energy exist in literature

387 (e.g. Münster et al., 2013, Mathiesen et al., 2009, Fruergaard et al., 2009); this may at 388 least partly be related to the overall LCA assessment approach, i.e. whether attributional 389 or consequential modeling is applied. While attributional studies may include a mix or 390 average of energy sources in a region, consequential LCA studies should involve the 391 marginal technologies responding to an induced change in the energy system 392 (Weidema, 2003, Weidema et al., 1999). 
In 197 case-studies energy substitution was included. Of these about $46 \%$

394 applied the local energy mix for the substitution, while $34 \%$ used a marginal energy 395 technology (Figure 10, middle). In $9 \%$ of the studies, energy substitution was modeled

396 as direct substitution of a fuel, e.g. in the case of avoided consumption of coal in case of 397 co-combustion in cement-kilns or power plants. However, as the overall modeling 398 approach (attributional vs. consequential) was specified only in relatively few cases, it 399 was not possible to assess whether energy substitution was performed consistently with 400 the modeling approach.

Very few case-studies, $3 \%$ (Figure 10, right), based decisions regarding energy substitution on energy modeling (e.g. Bergsdal et al., 2005). Involving energy modeling, i.e. modeling the consequences of an induced change in the energy supply system from WtE, indicates a consequential approach to quantification of the environmental impacts from $\mathrm{WtE}$ and an interest in regional conditions covered by the energy model. A more generic approach would be to quantify energy substitution based on scenario analysis, e.g. testing different possibilities for substituted fuels (e.g. Tonini et al., 2013). About $33 \%$ of the case-studies applied scenario analysis as basis for energy substitution, while $43 \%$ of the cases involved an energy mix based on literature data. In $21 \%$ of the cases, no explanation was provided regarding energy substitution.

\section{$412 \quad 3.3 .4$ Sensitivity and uncertainty analysis}

413 Several approaches for assessing uncertainties within waste LCA exist (e.g. Wang and 414 Shen, 2013, Clavreul et al., 2013, Clavreul et al., 2012). Accepting the validity of the 415 mathematical models involved in the LCA calculations, studies should address both 416 scenario and parameter uncertainties to evaluate the robustness of the LCA conclusions. 417 Although recommended in international guidelines (e.g. Hauschild et al., 2012), $46 \%$ of 
418 the case-studies did not include any assessment of uncertainties (see Figure 11). About

$41929 \%$ of the cases included sensitivity analysis on selected parameters, while scenario 420 uncertainties were only evaluated in $41 \%$ of the case-studies. Detailed quantification of 421 uncertainties, i.e. uncertainty propagation, was included in only $5 \%$ of the case-studies.

422 This clearly indicates that the robustness of the majority of LCA results provided in

423 literature for $\mathrm{WtE}$ technologies is very poorly evaluated and the applicability of results 424 may be questionable.

\subsection{Overall conclusions from the LCA results}

427 Most of the reviewed studies focused on comparing WtE technologies with other 428 alternatives or included $\mathrm{WtE}$ as part of mixed scenarios with a variety of waste 429 technologies. For this reason, and because of possible variations in the technological system (e.g. waste composition, technical performance, and framework conditions), it was therefore not possible to single out one WtE technology over another. However, some overall trends could be observed (see Table S12, supplementary materials).

The majority of studies ( 25 out of 29 scientific articles) comparing recycling and

434 landfilling with WtE confirmed the waste hierarchy (recycling $>\mathrm{WtE}>$ landfilling) for 435 the waste materials investigated. The remaining studies concluded that WtE was 436 preferable or comparable to recycling of paper and plastic (e.g. Manfredi et al., 2011).

437 Generally, these differences were a consequence of differences in assumptions 438 regarding energy recovery efficiencies and the substituted energy (e.g. substituting 439 natural gas or an average mix decreased the environmental benefits associated with 440 WtE). Regardless of assumptions, all studies recommended that recycling of WEEE, 441 metals and C\&D waste was preferable over incineration (e.g. Hischier et al., 2005, Ortiz 442 et al., 2010, Scharnhorst et al., 2006, Wäger et al., 2011). This was mainly due to the 
443 significant environmental savings from avoided virgin production and low energy 444 recovery from these fractions.

445 Most studies (25 out of 29 scientific articles) clearly indicated WtE as preferable 446 over landfilling. A few studies concluded landfilling to be preferable for specific 447 material fractions and under specific assumptions for the energy systems: plastic bags 448 (Khoo et al., 2010), specific material fractions such as paper and plastic when a limited 449 LCA time horizon was considered (Moberg et al., 2005), packaging waste (Wollny et 450 al., 2001), and RDF when the substituted energy was based on natural gas (Montejo et 451 al., 2013). Most of these results are not surprising: state-of-the-art landfilling may 452 induce significant $\mathrm{CO}_{2}$ and other environmental savings related to carbon sequestration 453 and energy recovery, and may perform comparable to $\mathrm{WtE}$ for specific waste fractions 454 and/or under specific energy system conditions as documented in e.g. Tonini et al. 455 (2013), Manfredi et al. (2011), and Manfredi et al. (2009). Only few studies compared pyrolysis and gasification with direct combustion, 457 incineration, and co-combustion in power plants or cement kilns (Saft, 2007, Bientinesi 458 and Petarca, 2009, Nakakubo et al., 2012, Assefa et al., 2005, Gunamantha and Sarto, 459 2012, Hellweg et al., 2005). Overall these studies found pyrolysis and gasification 460 preferable over incineration and co-combustion in cement kilns. Only one case 461 (Nakakubo et al., 2012) pyrolysis and co-combustion in cement kilns were found 462 comparable (sludge treatment). In another case (Hellweg et al., 2005), incineration and 463 gasification were found comparable for the non-toxic impact categories, but gasification 464 appeared better for the toxic categories due to an advanced metal recovery system for 465 slags. In all cases, the assumptions regarding energy and metal recovery efficiencies 466 were crucial for the results. Often, the inventory data applied for incineration did not 
represent state-of-the-art technologies and the technological scope of the compared $\mathrm{WtE}$

468 technologies were not always consistent.

469 No clear recommendation regarding RDF co-combustion in power plants or 470 cement kilns compared with direct incineration of untreated MSW could be found.

471 Three studies (Arena et al., 2003, Belboom et al., 2011, Houillon and Jolliet, 2005)

472 indicated incineration as preferable, while four (Cherubini et al., 2009, Blengini et al., 473 2012, Rigamonti et al., 2012, Ning et al., 2013) highlighted co-combustion as the best 474 option. Following this trend, also Tsiliyannis (1999) and Fruergaard and Astrup (2011) 475 showed a comparable performance for the non-toxic impact categories, mainly related 476 to the energy recovery. However, Fruergaard and Astrup (2011) also highlighted that 477 the improved flue-gas cleaning at waste incinerators (stricter emissions limits for $\mathrm{Hg}$, 478 As, heavy metals, dioxins, etc.) may outperform that of coal-fired power plants, thus 479 inducing important savings in the toxic categories.

480

\subsection{Critical inconsistencies in existing literature}

482 Overall, very few of the reviewed LCA studies provided sufficient description of goal 483 and scope of the LCA modeling and of the technologies included in the assessment. 484 Omitting this information prevents the necessary linking between the functional unit, 485 the waste composition and the WtE technology assessed, and further renders it 486 impossible to evaluate whether selected technical parameters match the temporal and 487 geographical scope of the assessment. Most studies in literature omitted key parts of the 488 technology system in the LCA modeling, e.g. air-pollution-control, residue 489 management, and capital goods, which may significantly affect the overall LCA results.

490 In cases where specific technology elements (e.g. air-pollution-control systems) were in 
491 fact included, or appeared to be included, the underlying data were often very poorly

492 described.

493 In addition to the scope and technology aspects, also the description of the LCA

494 modeling approaches was often weak. This means that the validity of calculation

495 principles could not be assessed and ultimately reproduced. With energy recovery

496 modeling as an example, only $39 \%$ of the studies provided both the LHV of the waste

497 input and heat and electricity efficiencies, thereby allowing the reader to reproduce

498 calculations. In all other cases, the validity of the energy calculations could not be fully

499 examined.

500 While the LCA field has developed tremendously over the recent two decades

501 and an acceptance of the complexities related to waste LCA modeling is increasing, this

502 review clearly suggests that the quality of the peer-review process involved in scientific publishing of WtE LCA studies may be questionable.

504

\subsection{Recommendations for state-of-the-art LCA of WtE technologies}

506 Based on the reviewed literature, a range of practical recommendations for performing state-of-the-art LCA of WtE technologies and systems were identified:

- The LCA assessment approach, i.e. consequential or attributional, should be clearly stated. Most of the reviewed studies omitted this.

511 - The functional unit should not only describe the service provided by the system

512 (e.g. utilization of $1 \mathrm{Mg}$ of waste) but should be supplemented with a transparent

513 description of temporal, geographical, and technological scope.

514 - Choice of technologies and recovery efficiencies should reflect the geographical, 515 temporal, and technological scope. New emerging technologies not yet 
demonstrated in full-scale, should be compared with alternative technologies appropriate for the time period when a full-scale installation of the technology can be expected (e.g. Tonini et al., 2013). This means that performance, plant capacity, efficiencies, emission control, etc. of alternative technologies should be forecasted and matched, and the comparison not be based on old landfills or poorly performing incinerators represented by obsolete technologies and datasets.

- LHV, material and preferably chemical composition of the waste should be reported, or alternatively a clear reference to the data source should be provided. Similar for the inventory data (particularly air emissions and consumption data). For green accounts and other non-peer-reviewed sources, (current) web links should be provided with the reference.

- Energy substitution principles (marginal vs. average mix) should reflect the LCA assessment approach (consequential vs. attributional) and the temporal scope. Future marginal energy sources could be identified for example based on national energy plans or projections from energy agencies (e.g. IEA). Political targets could also be used to justify energy substitution as such targets may likely promote technology implementation/phase-out.

- Detailed descriptions of mass, substance and energy flows in the WtE technology system should be provided (e.g. in supporting materials). Examples of consistent and transparent LCI reporting could be found in Blengini et al. (2012) or Rigamonti et al. (2012).

- Uncertainty aspects should be systematically addressed, either by sensitivity analysis or by propagation of uncertainties. The type of uncertainty assessment should be clearly described (e.g. following the principles by Clavreul et al., 
2012). Examples of this can be found in Clavreul et al. (2013), Clavreul et al.

542 (2012), and Tonini et al. (2012).

- Environmental impacts from capital goods should be addressed if possible,

\section{Conclusions}

558 The review included 136 peer-reviewed journal articles involving life cycle assessment 559 (LCA) of the following waste-to-energy (WtE) technology types: incineration, co560 combustion, pyrolysis, and gasification. In total, these journal articles reported results

561 from 250 individual case-studies or scenarios. By far the most case-studies assessed 562 incineration, while relatively few studies addressed technologies such as 563 pyrolysis/gasification and co-combustion in detail. Very few of the reviewed studies 564 provided a sufficient description of i) goal and scope of the assessment, ii) the 565 technologies included, and the iii) the calculation principles applied for quantification of 
emissions and energy recovery. Consequently, the LCA results reported in the studies

567 could be verified only in very few cases. This clearly questions the peer-review process

568 involved prior to publication of the studies, but also significantly limits the applicability

569 of inventory data and LCA results provided by the existing studies. The overview of 570 assumptions and data applied in existing LCA literature offered by this review provides

571 a consistent platform for future studies to ensure transparency and clear argumentation

572 for assessment choices when addressing $\mathrm{WtE}$ technologies.

573

574 Supplementary Material

575 The supplementary material includes: i) a full list of references of the 136 reviewed

576 journal articles, ii) detailed review-metrics for all 250 case-studies, iii) list of extracted

577 inventory data, and iv) overview of main conclusions in the LCA studies.

578

\section{$579 \quad$ Literature}

580 Arena, U., Mastellone, M.L., Perugini, F., 2003. The environmental performance of 581 alternative solid waste management options: a life cycle assessment study. Chem. Eng. J. 96, 207-222.

583

Assefa, G., Eriksson, O., Frostell, B., 2005. Technology assessment of thermal 584 treatment technologies using ORWARE. Energ. Conv. Manage. 46, 797-819.

Astrup, T., Riber, C., Pedersen, A.J., 2011. Incinerator performance: effects of changes 586 in waste input and furnace operation on air emissions and residues. Waste Manage. $587 \quad$ Res. 29, 57-68.

588 Belboom, S., Renzoni, R., Verjans, B., Leonard, A., Germain, A., 2011. A life cycle 589 assessment of injectable drug primary packaging: comparing the traditional process 590 in glass vials with the closed vial technology (polymer vials). Int. J. Life Cycle 591 Assess. 16, 159-167. 
Bergsdal, H., Stromman, A., Hertwich, E., 2005. Environmental assessment of two waste incineration strategies for central Norway. Int. J. Life Cycle Assess. 10, 263 272.

Bernstad, A., la Cour Jansen, J., 2011. A life cycle approach to the management of household food waste - A Swedish full-scale case study. Waste Manage. 31, 18791896.

Bientinesi, M., Petarca, L., 2009. Comparative environmental analysis of waste brominated plastic thermal treatments. Waste Manage. 29, 1095-1102.

601

Birgisdóttir H., Bhander G., Hauschild M.Z., Christensen T.H., 2007. Life cycle assessment of disposal of residues from municipal solid waste incineration: recycling of bottom ash in road construction or landfilling in Denmark evaluated in the ROAD-RES model. Waste Manage. 27, S75-84.

Blengini, G.A., Fantoni, M., Busto, M., Genon, G., Zanetti, M.C., 2012. Participatory approach, acceptability and transparency of waste management LCAs: Case studies of Torino and Cuneo. Waste Manage. 32, 1712-1721.

Boesch, M.E., Vadenbo, C., Saner, D., Huter, C., Hellweg, S., 2014. An LCA model for waste incineration enhanced with new technologies for metal recovery and application to the case of Switzerland. Waste Manage. 34, 378-389.

Brogaard, L.K., Riber, C., Christensen, T.H., 2013. Quantifying capital goods for waste

612 Brogaard, L.K., Christensen, T.H., 2012. Quantifying capital goods for collection and transport of waste. Waste Manage. Res. 30, 1243-1250.

614 Cherubini, F., Bargigli, S., Ulgiati, S., 2009. Life cycle assessment (LCA) of waste 615 management strategies: Landfilling, sorting plant and incineration. Energy 34, 21166162123.

617 Christensen, T.H., Simion, F., Tonini, D., Møller, J., 2009. Global warming factors 618 modelled for 40 generic municipal waste management scenarios. Waste Manage. 619 Res. 27, 871-884.

620 Clavreul, J., Guyonnet, D., Christensen, T.H., 2012. Quantifying uncertainty in LCA621 modelling of waste management systems. Waste Manage. 32, 2482-2495.

622 Clavreul, J., Guyonnet, D., Tonini, D., Christensen, T.H., 2013. Stochastic and 623 epistemic uncertainty propagation in LCA. Int. J. Life Cycle Assess. 18, 1393-1403. 
624 Damgaard, A., Riber, C., Fruergaard, T., Hulgaard, T., Christensen, T.H., 2010. Life-

625

626

627

628

629

630

631

632

633

634

635

636

637

638

639

640

641

642

643

644

645

646

647

648

649

650

651

652

653 cycle-assessment of the historical development of air pollution control and energy recovery in waste incineration. Waste Manage. 30, 1244-1250.

Ekvall, T., Assefa, G., Björklund, A., Eriksson, O., Finnveden, G., 2007. What lifecycle assessment does and does not do in assessments of waste management. Waste Manage. 27, 989-996.

Eriksson, O., Finnveden, G., Ekvall, T., Björklund, A., 2007. Life cycle assessment of fuels for district heating: A comparison of waste incineration, biomass- and natural gas combustion. Energy Policy 35, 1346-1362.

Finnveden, G., 1999. Methodological aspects of life cycle assessment of integrated solid waste management systems. Resour. Conserv. Recycl. 26, 173-187.

Finnveden, G., Björklund, A., Reich, M.C., Eriksson, O., Sörbom, A., 2007. Flexible and robust strategies for waste management in Sweden. Waste Manage. 27, S1-S8.

Finnveden, G., Hauschild, M.Z., Ekvall, T., Guinée, J., Heijungs, R., Hellweg, S., Koehler, A., Pennington, D., Suh, S., 2009. Recent developments in Life Cycle Assessment. J. Environ. Manage. 91, 1-21.

Finnveden, G., Johansson, J., Lind, P., Moberg, Å., 2005. Life cycle assessment of energy from solid waste-part 1: general methodology and results. J. Clean. Prod. $13,213-229$.

Fruergaard, T., Astrup, T., 2011. Optimal utilization of waste-to-energy in an LCA perspective. Waste Manage. 31, 572-582.

Fruergaard, T., Christensen, T.H., Astrup, T., 2010. Energy recovery from waste incineration: Assessing the importance of district heating networks. Waste Manage. 30, 1264-1272.

Fruergaard, T., Hyks, J., Astrup, T., 2010. Life-cycle assessment of selected management options for air pollution control residues from waste incineration. Sci. Total Environ. 408, 4672-4680.

Fruergaard, T., Astrup, T., Ekvall, T., 2009. Energy use and recovery in waste management and implications for accounting of greenhouse gases and global warming contributions. Waste Manage. Res. 27, 724-737. 
654 Gunamantha, M., Sarto, 2012. Life cycle assessment of municipal solid waste treatment to energy options: Case study of KARTAMANTUL region, Yogyakarta. Renew. Energ. 41, 277-284.

Hauschild, M., Goedkoop, M., Guinée, J., Heijungs, R., Huijbregts, M., Jolliet, O., Margni, M., Schryver, A., Humbert, S., Laurent, A., Sala, S., Pant, R., 2012. Identifying best existing practice for characterization modeling in life cycle impact assessment. Int. J. Life Cycle Assess. 18, 1-15.

Hellweg, S., Doka, G., Finnveden, G., Hungerbuhler, K., 2005. Assessing the ecoefficiency of end-of-pipe technologies with the environmental cost efficiency indicator - A case study of solid waste management. J. Ind. Ecol. 9, 189-203.

Hellweg, S., Hofstetter, T., Hungerbuhler, K., 2001. Modeling waste incineration for life-cycle inventory analysis in Switzerland. Environ. Model. Assess. 6, 219-235.

Hischier, R., Wäger, P., Gauglhofer, J., 2005. Does WEEE recycling make sense from an environmental perspective? The environmental impacts of the Swiss take-back and recycling systems for waste electrical and electronic equipment (WEEE). Environ. Impact Assess. Rev. 25, 525-539.

Hong, R.J., Wang, G.F., Guo, R.Z., Cheng, X., Liu, Q., Zhang, P.J., Qian, G.R. 2006. Life cycle assessment of BMT-based integrated municipal solid waste management: Case study in Pudong, China. Resour. Conserv. Recy. 49, 129-146

Houillon, G., Jolliet, O., 2005. Life cycle assessment of processes for the treatment of wastewater urban sludge: energy and global warming analysis. J. Clean. Prod. 13, 287-299.

ISO, 2006a. Environmental Management-Life Cycle Assessment-Principles and Framework, 2nd ed.; ISO 14040; 2006-07-01; ISO: Geneva, 2006.

ISO, 2006b. Environmental Management-Life Cycle Assessment-Requirements and Guidelines, 1st ed.; ISO 14040; 2006-07-01; ISO: Geneva, 2006.

680 ISWA, 2012. Waste-to-Energy State-of-the-Art-Report. Statistics, $6^{\text {th }}$ edition. Ramboell: 681 Copenhagen (Denmark). Available at http://www.waste-management682 world.com/content/dam/wmw/online683 articles/documents/2013/ISWA_WtE_State_of_the_Art_Report_2012_08_FV.pdf 684 (accessed March 2014). 
685 Khoo, H.H., 2009. Life cycle impact assessment of various waste conversion 686 technologies. Waste Manage. 29, 1892-1900.

687 Khoo, H.H., Lim, T.Z., Tan, R.B.H., 2010. Food waste conversion options in 688 Singapore: Environmental impacts based on an LCA perspective. Sci. Total Environ. $689408,1367-1373$.

690 Laurent, A., Bakas, I., Clavreul, J., Bernstad, A., Niero, M., Gentil, E., Hauschild, M.Z., 691 Christensen, T.H., 2014a. Review of LCA studies of solid waste management 692 systems - Part I: Lessons learned and perspectives. Waste Manage. 34, 573-588.

693 Laurent, A., Clavreul, J., Bernstad, A., Bakas, I., Niero, M., Gentil, E., Christensen, 694 T.H., Hauschild, M.Z., 2014b. Review of LCA studies of solid waste management 695 systems - Part II: Methodological guidance for a better practice. Waste Manage. 34, 696 589-606.

697 Liamsanguan, C., Gheewala, S.H., 2007. Environmental assessment of energy 698 production from municipal solid waste incineration. Int. J. Life Cycle Assess. 12, $699 \quad 529-536$.

700 Manfredi, S., Tonini, D., Christensen, T.H., Scharff, H., 2009. Landfilling of waste: 701 accounting of greenhouse gases and global warming contributions. Waste Manage. 702 Res. 27, 825-836.

703 Manfredi, S., Tonini, D., Christensen, T.H., 2011. Environmental assessment of 704 different management options for individual waste fractions by means of life-cycle 705 assessment modelling. Resour. Conserv. Recycl. 55, 995-1004.

706 Mathiesen, B.V., Münster, M., Fruergaard, T., 2009. Uncertainties related to the 707 identification of the marginal energy technology in consequential life cycle 708 assessments. J. Clean. Prod. 17, 1331-1338.

709 Merrild, H., Larsen, A.W., Christensen, T.H., 2012. Assessing recycling versus 710 incineration of key materials in municipal waste: The importance of efficient energy 711 recovery and transport distances. Waste Manage. 32, 1009-1018.

712 Moberg, Å., Finnveden, G., Johansson, J., Lind, P., 2005. Life cycle assessment of 713 energy from solid waste - part 2: landfilling compared to other treatment methods. J. 714 Clean. Prod. 13, 231-240. 
715 Møller, J., Munk, B., Crillesen, K., Christensen, T.H., 2011. Life cycle assessment of 716 selective non-catalytic reduction (SNCR) of nitrous oxides in a full-scale municipal solid waste incinerator. Waste Manage. 31, 1184-1193.

Montejo, C., Tonini, D., Márquez, M.C., Astrup, T.F., 2013. Mechanical-biological treatment: Performance and potentials. An LCA of 8 MBT plants including waste characterization. J. Environ. Manage. 128, 661-673.

Morselli, L., Luzi, J., Robertis, C.D., Vassura, I., Carrillo, V., Passarini, F., 2007. Assessment and comparison of the environmental performances of a regional incinerator network. Waste Manage. 27, S85-S91.

Münster, M., Finnveden, G., Wenzel, H., 2013. Future waste treatment and energy systems - examples of joint scenarios. Waste Manage. 33, 2457-2464.

Nakakubo, T., Tokai, A., Ohno, K., 2012. Comparative assessment of technological systems for recycling sludge and food waste aimed at greenhouse gas emissions reduction and phosphorus recovery. J. Clean. Prod. 32, 157-172.

Ning, S., Chang, N., Hung, M., 2013. Comparative streamlined life cycle assessment for two types of municipal solid waste incinerator. J. Clean. Prod. 53, 56-66.

Ortiz, O., Pasqualino, J.C., Castells, F., 2010. Environmental performance of construction waste: Comparing three scenarios from a case study in Catalonia, Spain. Waste Manage. 30, 646-654.

Rigamonti, L., Grosso, M., Møller, J., Martinez Sanchez, V., Magnani, S., Christensen, T.H., 2014. Environmental evaluation of plastic waste management scenarios. Resour. Conserv. Recycl. 85, 42-53.

Rigamonti, L., Grosso, M., Biganzoli, L., 2012. Environmental Assessment of RefuseDerived Fuel Co-Combustion in a Coal-Fired Power Plant. J. Ind. Ecol. 16(5), 748760.

Scipioni, A., Mazzi, A., Niero, M., Boatto, T., 2009. LCA to choose among alternative design solutions: The case study of a new Italian incineration line. Waste Manage.

743 Saft, R.J., 2007. Life cycle assessment of a pyrolysis/gasification plant for hazardous 744 paint waste. Int. J. Life Cycle Assess. 12, 230-238. 
Scharnhorst, W., Hilty, L.M., Jolliet, O., 2006. Life cycle assessment of second generation $(2 \mathrm{G})$ and third generation $(3 \mathrm{G})$ mobile phone networks. Environ. Int. 32, 656-675.

Song, Q., Wang, Z., Li, J., 2013. Environmental performance of municipal solid waste strategies based on LCA method: a case study of Macau. J. Clean. Prod. 57, 92-100.

Tonini, D., Astrup, T., 2012. Life-cycle assessment of a waste refinery process for enzymatic treatment of municipal solid waste. Waste Manage. 32, 165-176.

Tonini, D., Hamelin, L., Wenzel, H., Astrup, T., 2012. Bioenergy Production from Perennial Energy Crops: A Consequential LCA of 12 Bioenergy Scenarios including Land Use Changes. Environ. Sci. Technol. 46, 13521-13530.

Tonini, D., Martinez-Sanchez, V., Astrup, T.F., 2013. Material Resources, Energy, and Nutrient Recovery from Waste: Are Waste Refineries the Solution for the Future? Environ. Sci. Technol. 47, 208962-8969.

Tsiliyannis, C.A., 1999. Report: Comparison of environmental impacts from solid waste treatment and disposal facilities. Waste Management and Research 17, 231-241.

Tunesi, S., 2011. LCA of local strategies for energy recovery from waste in England, applied to a large municipal flow. Waste Manage. 31, 561-571.

Turconi, R., Boldrin, A., Astrup, T., 2013. Life cycle assessment (LCA) of electricity generation technologies: Overview, comparability and limitations. Renew. Sust. Energ. Rev. 28, 555-565.

Turconi, R., Butera, S., Boldrin, A., Grosso, M., Rigamonti, L., Astrup, T., 2011. Life cycle assessment of waste incineration in Denmark and Italy using two LCA models. Waste Manage. Res. 29, 78-90.

Wäger, P.A., Hischier, R., Eugster, M., 2011. Environmental impacts of the Swiss collection and recovery systems for Waste Electrical and Electronic Equipment (WEEE): A follow-up. Sci. Total Environ. 409, 1746-1756.

Wang, E., Shen, Z., 2013. A hybrid Data Quality Indicator and statistical method for improving uncertainty analysis in LCA of complex system - application to the whole-building embodied energy analysis. J. Clean. Prod. 43, 166-173.

Weidema, B., 2003. Market information in life cycle assessment. Environmental project 863. Available at: http://www.norlca.org/resources/780.pdf (accessed January 2014). 
776 Weidema, B., Frees, N., Nielsen, A.M., 1999. Marginal production technologies for 777 Life Cycle Inventories. Int. J. Life Cycle Assess. 4, 48-56.

778 Wollny, V., Dehoust, G., Fritsche, U.R., Weinem, P., 2001. Comparison of Plastic

779 Packaging Waste Management Options: Feedstock Recycling versus Energy 780 Recovery in Germany. J. Ind. Ecol. 5, 49-63.

781 Zaman, A.U., 2010. Comparative study of municipal solid waste treatment technologies 782 using life cycle assessment method. Int. J. Environ. Sci. Technol. 7, 225-234.

783

784

785 


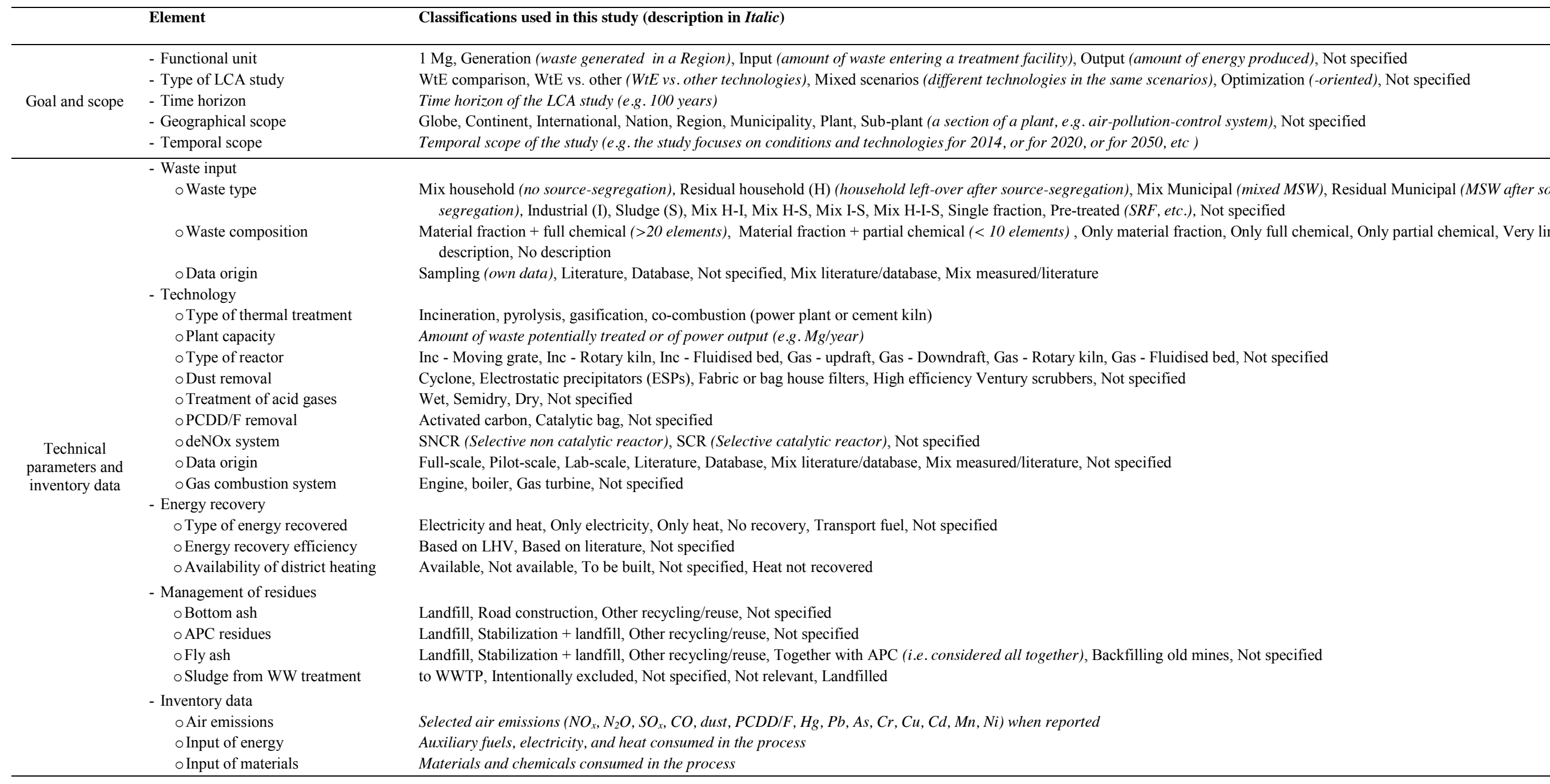


- LCA modeling approach

oMass/Energy b

Methodological - Capital goods

choices in LCA - Savings from energy production

modeling o Type of energy substituted

Energy substitution model

- Uncertainty/sensitivity analysis $\circ$ Type of uncertainty analysis
Mass+energy (TC), Only mass (TC), Only energy (TC), Mass+energy, Only mass, Only energy, No balance. TC: transfer coefficients (the balance explicitly uses transfer coeffict related to input of mass and chemicals, or energy)

Included, Intentionally excluded, Not specified

Fuel source (or mix of fuels) substituted by the electricity recovered in the scenario under assessment

Marginal, Average mix, Not specified 
790 Table 2. Overview of energy recovery efficiencies in case-studies reporting such data.

791 Average and standard deviation (st.dev.) is provided when more than two case-studies

792 was available. Gasification and pyrolysis efficiencies are based on gas-electricity and

793 gas-heat conversions only.

\begin{tabular}{|c|c|c|c|c|c|c|c|c|c|}
\hline & \multicolumn{3}{|c|}{ Gross electricity efficiency } & \multicolumn{3}{|c|}{ Net electricity efficiency } & \multicolumn{3}{|c|}{ Net heat efficiency } \\
\hline & $\begin{array}{l}\text { N. case- } \\
\text { studies }\end{array}$ & $\begin{array}{c}\text { Range } \\
(\%)\end{array}$ & $\begin{array}{c}\text { Average } \\
\pm \text { st.dev. } \\
(\%)\end{array}$ & $\begin{array}{c}\text { N. case- } \\
\text { studies }\end{array}$ & $\begin{array}{c}\text { Range } \\
(\%)\end{array}$ & $\begin{array}{c}\text { Average } \\
\pm \text { st.dev. } \\
(\%)\end{array}$ & $\begin{array}{l}\text { N. case- } \\
\text { studies }\end{array}$ & $\begin{array}{c}\text { Range } \\
(\%)\end{array}$ & $\begin{array}{c}\text { Average } \\
\pm \text { st.dev. } \\
(\%)\end{array}$ \\
\hline Incineration & 61 & $0-34$ & $21 \pm 7.0$ & 87 & $-2-30$ & $19 \pm 7.5$ & 68 & $0-87.7$ & $44 \pm 28.4$ \\
\hline Co-combustion in cement-kilns & 1 & 4.38 & - & 0 & - & - & 0 & - & - \\
\hline Gasification & 2 & $33-34$ & - & 5 & $14.5-27.2$ & $20 \pm 5.3$ & 2 & $33-45.5$ & - \\
\hline Pyrolysis & 1 & 18.0 & - & 1 & 15.25 & - & 1 & 70.3 & - \\
\hline Pyrolysis-gasification & 1 & 35.0 & - & 0 & - & - & 1 & 40.0 & - \\
\hline
\end{tabular}

795 


\section{List of figure captions}

797

798 Figure 1. Temporal development of LCA case-studies on thermal WtE technologies.

799 Bars indicate number of case-studies in individual years, left y-axis, while diamonds 800 represent the cumulative number of case-studies (244), right y-axis.

801

802 Figure 2. Overview of functional unit, goal of the LCA and waste types included in 803 the reviewed case-studies.

804

805 Figure 3. Overview of information provided on waste composition in the reviewed 806 case-studies.

807

808 Figure 4. Overview of thermal technologies included in the reviewed case-studies.

809

810 Figure 5. Overview of technical aspects related to air-pollution-control (APC) systems 811 in the reviewed case-studies.

812

813 Figure 6. Overview of energy recovery options and calculation principles in the 814 reviewed case-studies.

815

816 Figure 7. Overview of residues management in the reviewed case-studies.

818 Figure 8. Overview of overall LCI modeling approaches included in the reviewed 819 case-studies (TC: transfer coefficients). 
821 Figure 9. Overview of capital goods modeling in the reviewed case-studies.

822

823 Figure 10. Overview of energy substitution approaches in the reviewed case-studies.

824

825 Figure 11. Overview of sensitivity/uncertainty analysis in the reviewed case-studies.

826 
Case studies in 1995-2013

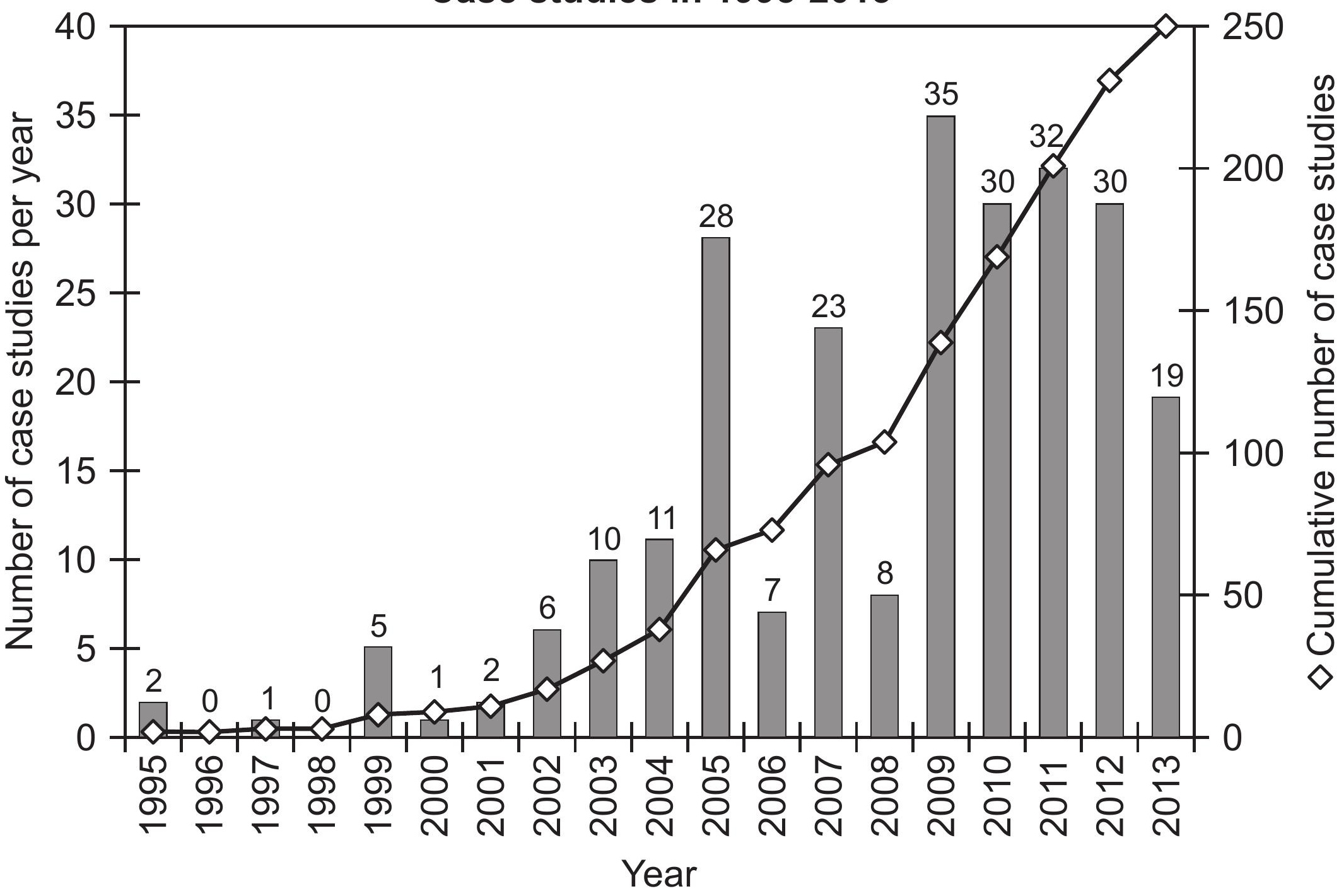


Figure 06

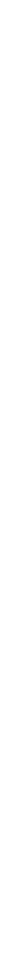



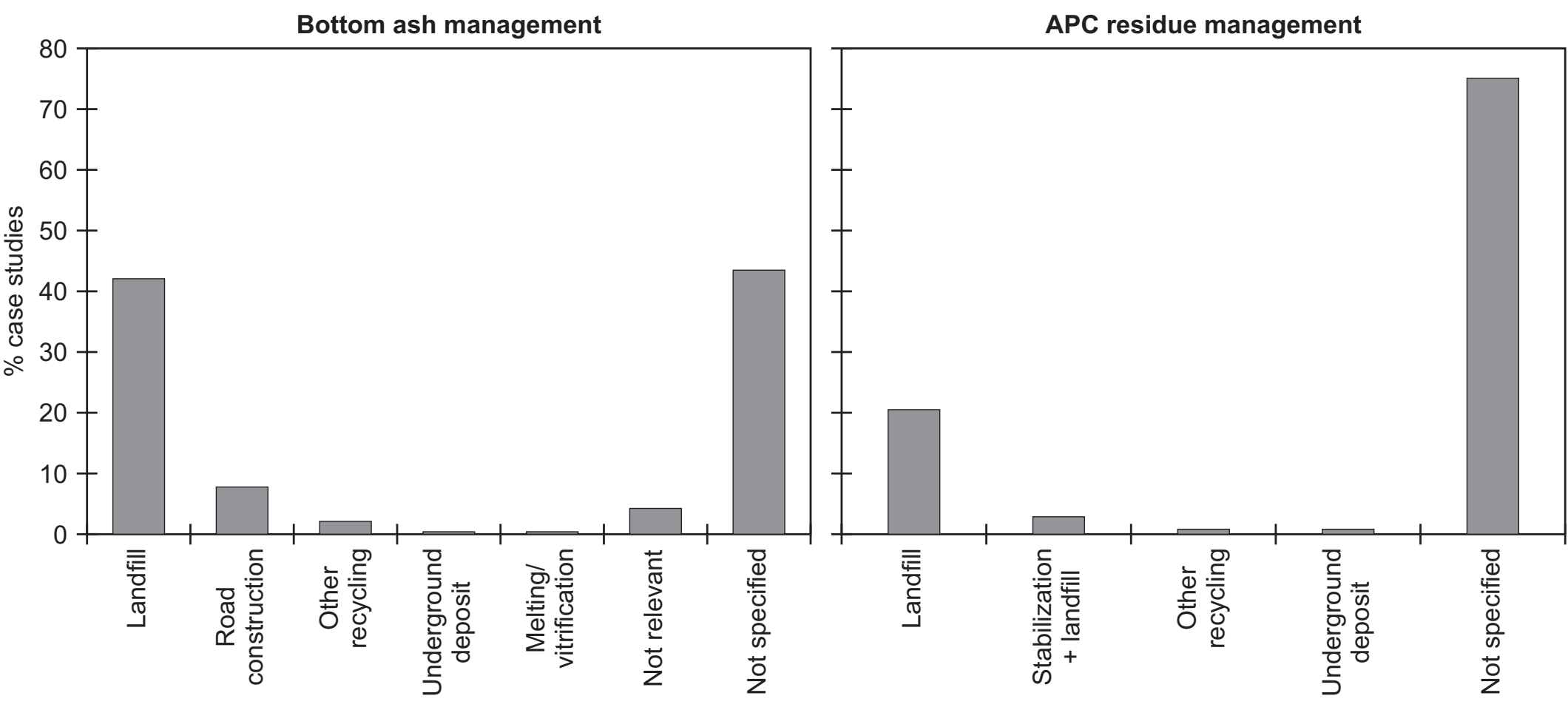

Fly ash management
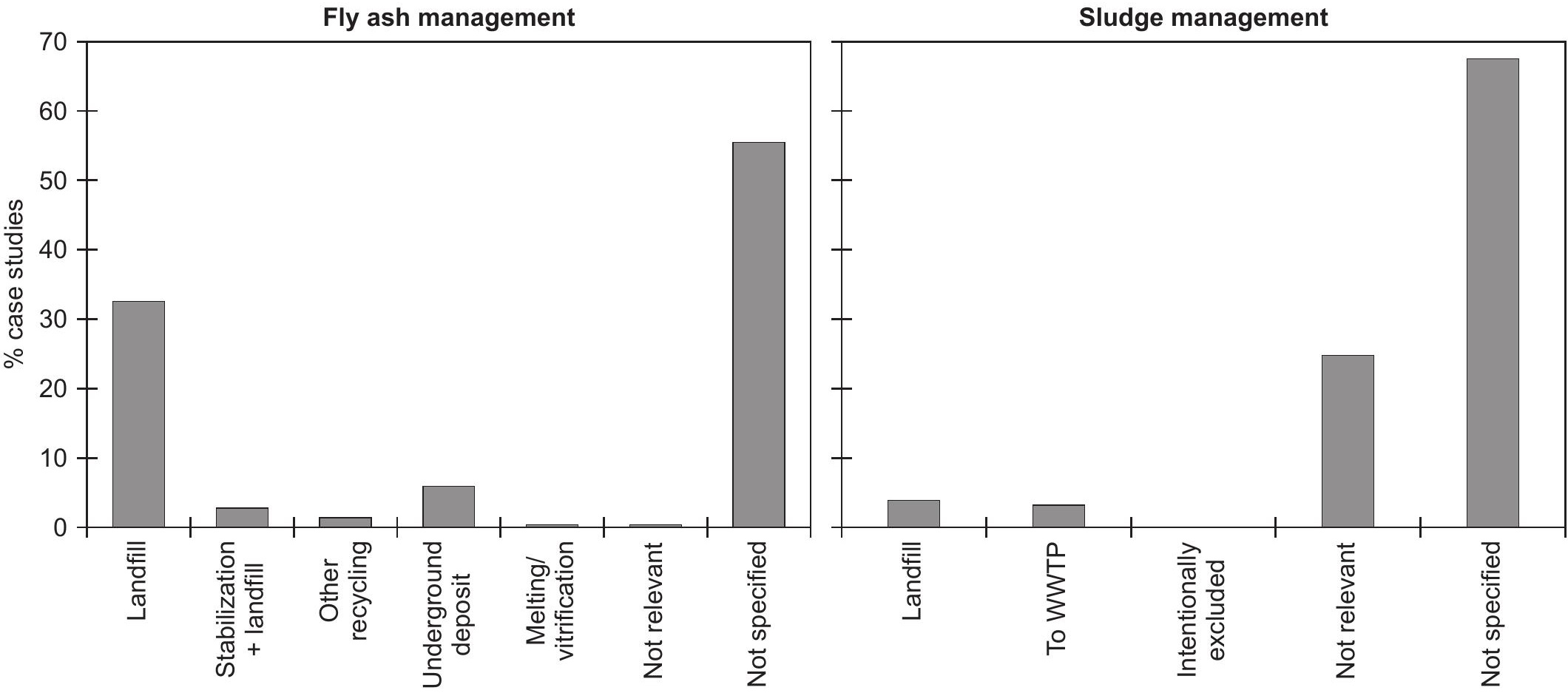
LCI modelling approach

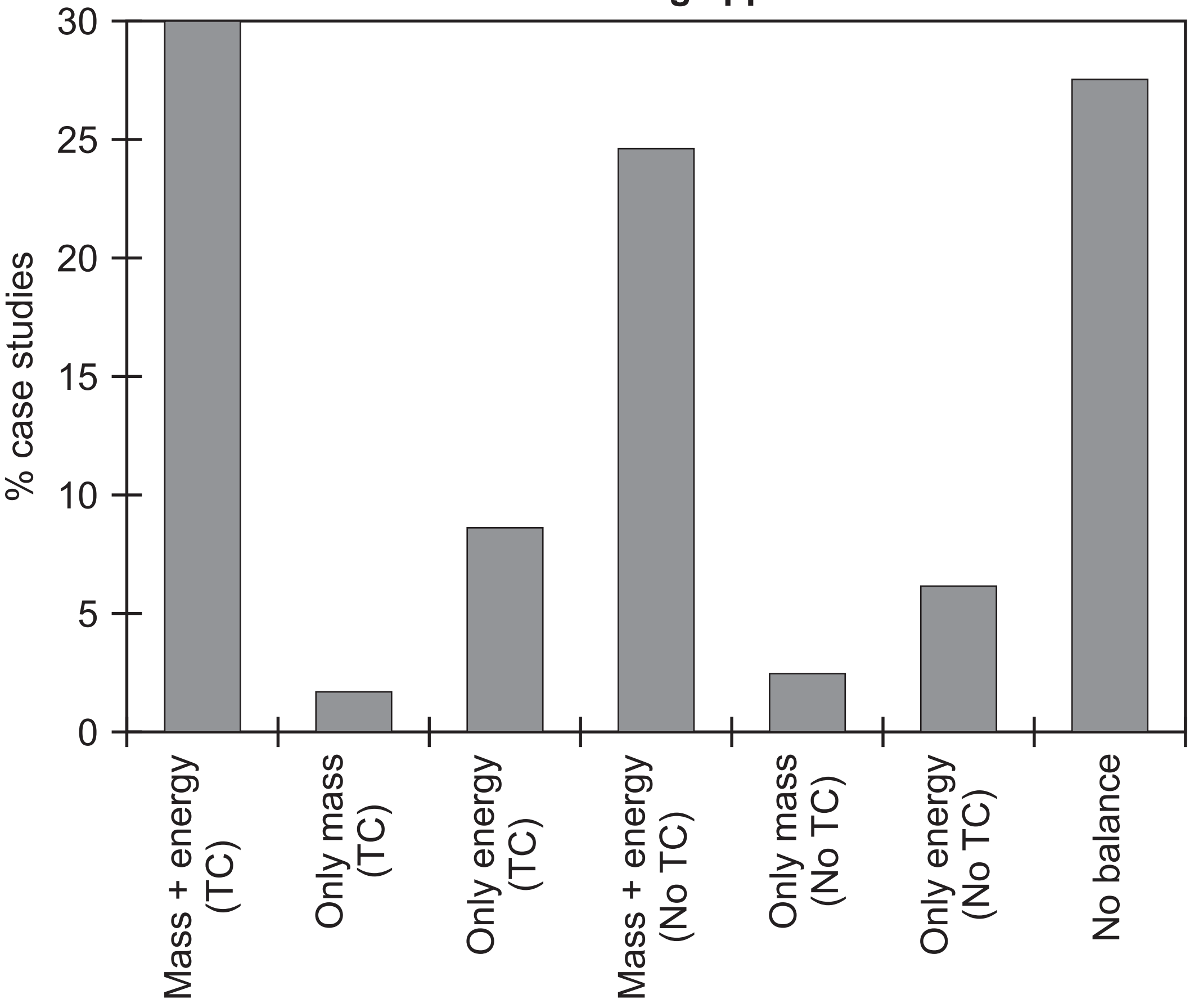




\section{Capital goods}

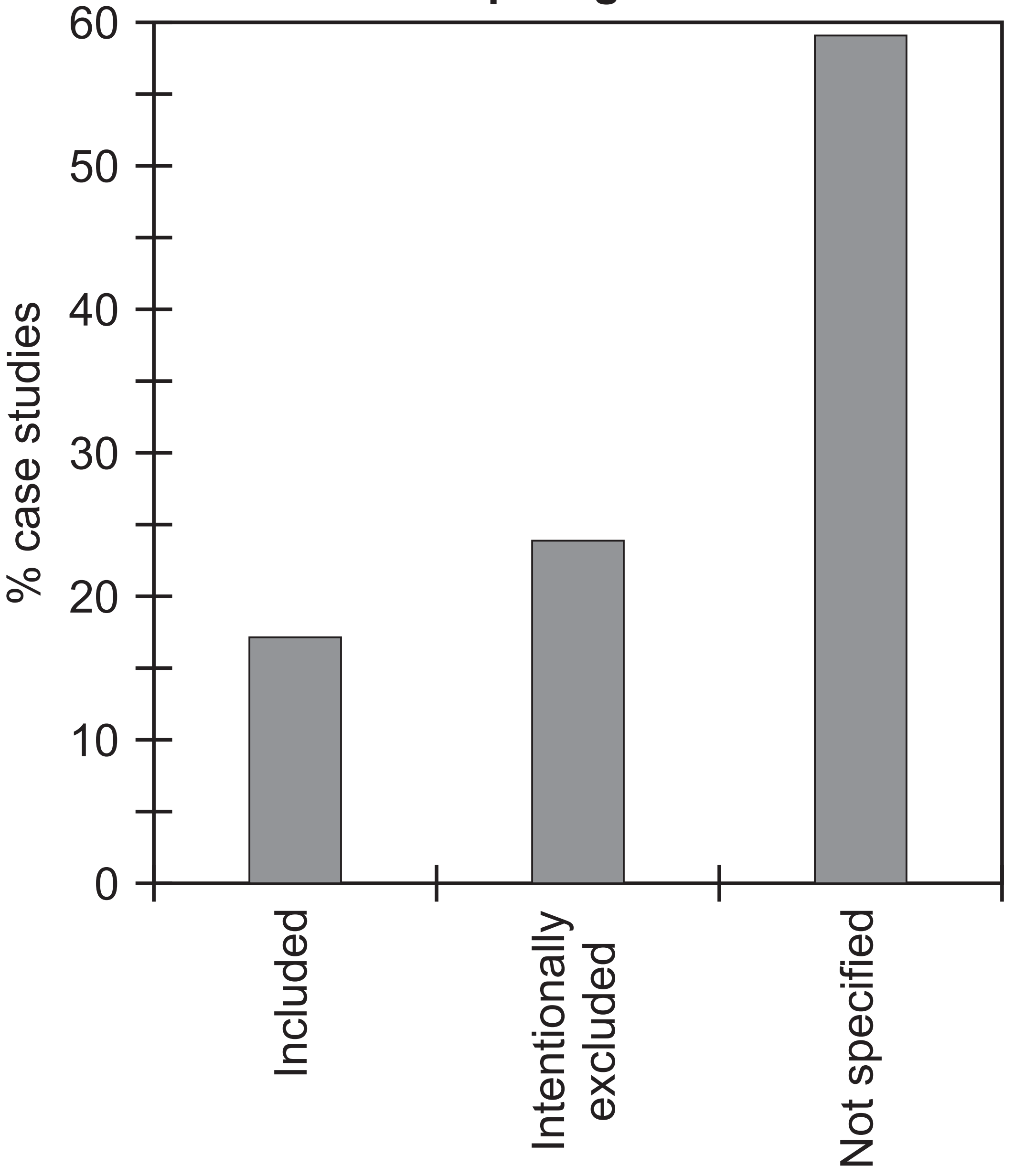



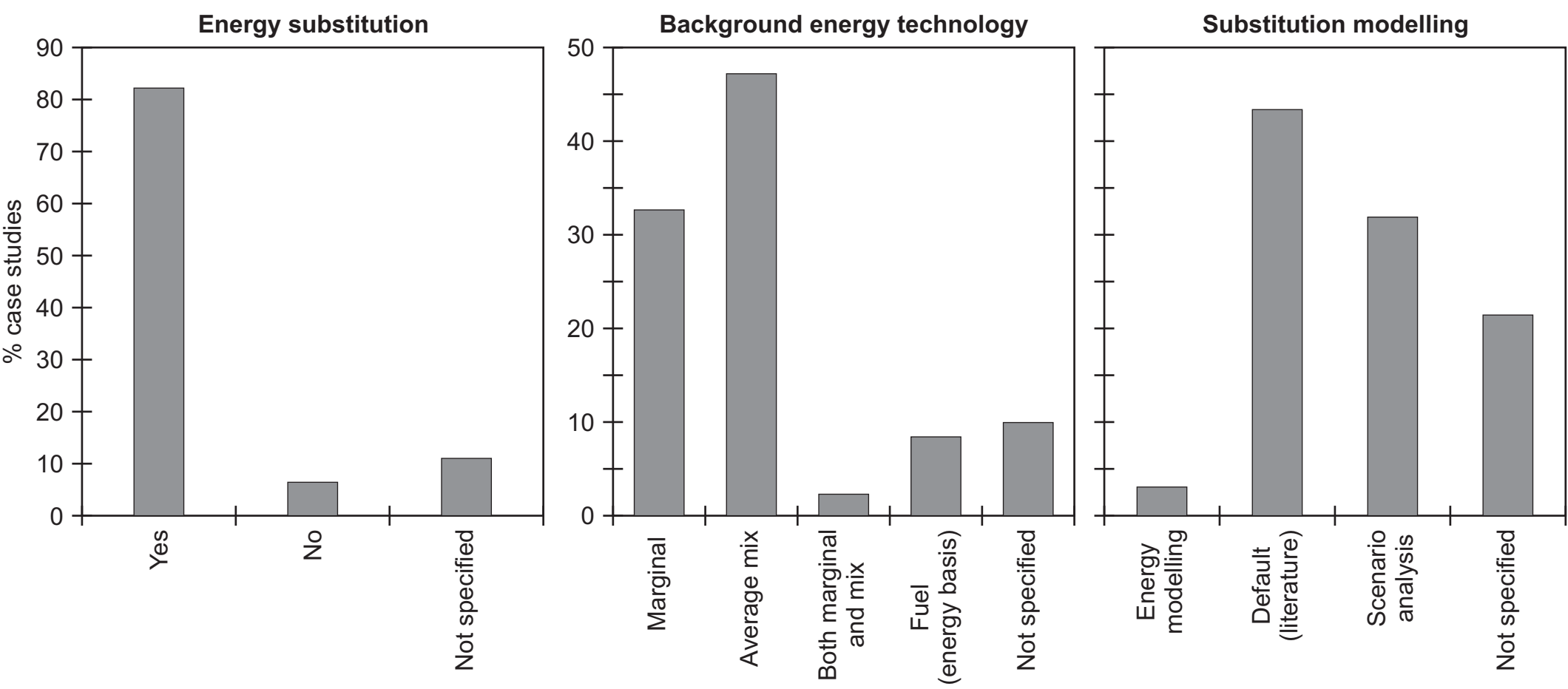


\section{Sensitivity/uncertainty analysis}

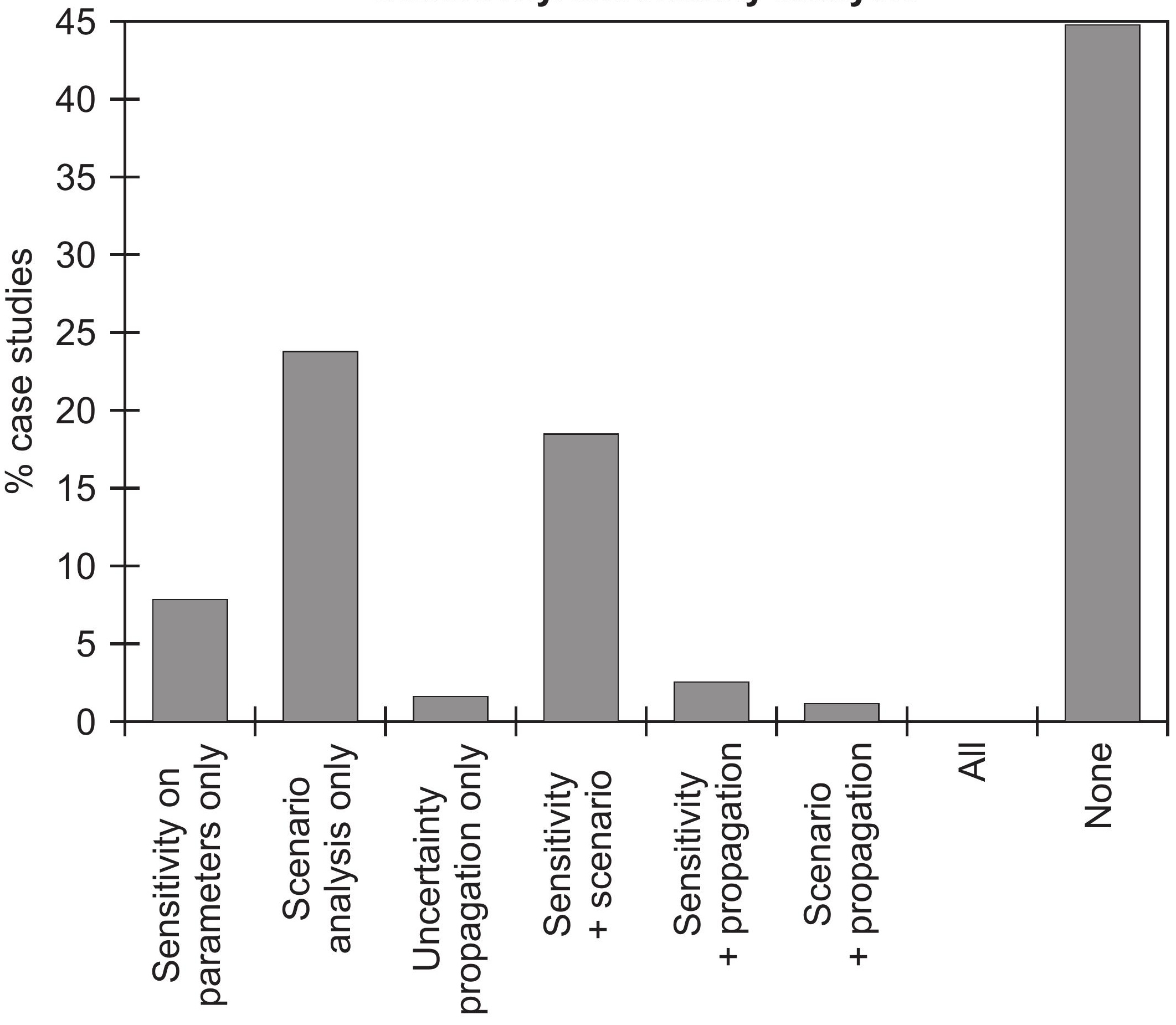

